Historic, archived document

Do not assume content reflects current scientific knowledge, policies, or practices. 

U. S. DEPARTMENT OF AGRICULTURE. BUREAU OF PLANT INDUSTRY-BULLETIN NO. 249.

B. T. GALLOWAY, Chief of Bureau.

\title{
THE BRANCHING HABITS OF EGYPTIAN COTTON.
}

\author{
BY \\ ARGYLE McLACHLAN, \\ Agent, Crop Acclimatization and Adaptation \\ Investigations.
}

Issued September 20, 1912.

WASHINGTON:

GOVERNMENT PRINTING OFFIOE.

.1912. 


\title{
BUREAU OF PLANT INDUSTRY.
}

\author{
Chief of Bureau, Beverly T. GaLloway. \\ Assistant Chief of Bureau, WILliam A. TAYLOR. \\ Editor, J. E. ROCK WELL. \\ Chief Clerk, JaMes E. Jones.
}

\section{Crop Acclinatization and adaptation Investigations.}

\section{SCIENTIFIC STAFF.}

O. F. Cook, Bionomist in Charge.

G. N. Collins, Botanist.

H. Pittier, Special Field Agent.

A. T. Anders, J. H. Kinsler, Argyle McLachlan, and D. A. Saunders, Agents.

C. H. Clark, C. B. Doyle, J. H. Kempton, and R. M. Meade, Assistants. 


\title{
LETTER OF TRANSMITTAL.
}

\author{
U. S. Department of Agriculture, \\ Bureau of Plant Industry, \\ OfFice of THe Chief, \\ Washington, D. C., Warch 12, 1912.
}

SIR: I have the honor to transmit herewith a paper entitled "The Branching Habits of Egyptian Cotton," by Mr. Argyle McLachlan, of this bureau, and to recommend its publication as Bulletin No. 249 of the bureau series. More definite information regarding the habits of branching of the Egyptian cotton has been required in developing a system of cultivation adapted to the irrigated districts of southern California and Arizona.

Respectfully,

Hon. James Wilson,

$$
\text { Secretary of Agriculture. }
$$

B. T. Galloway, Chief of Bureau. 



\section{CONTENTS.}

Page.

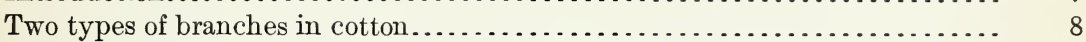

General characters of the branching habits of Egyptian cotton............ 8

Three branch zones in the Egyptian cotton plant....................... 8

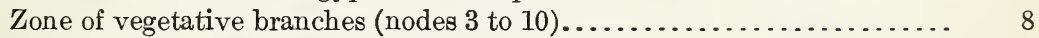

Zone of rudimentary branches, or transition zone................. 9

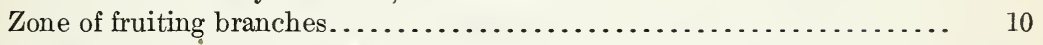

Regular sequence of branch development in Egyptian cotton............... 11

Distinction between fruiting and vegetative branches................... 12

Fruiting branches replaced by vegetative branches.................... 13

Transformation of fruiting branches into vegetative branches. . . . . . . . . . 14

Homology between large basal limbs and fruiting branches................ 14

Abortion of fruiting branches..................................... 15

Importance of selection for low fruiting branches on the main axis......... 16

Representation of branching habits by diagrams..................... 16

Characteristics of the fruiting habits of different acclimatized strains of Egyptian

cotton shown by the diagrams............................... 18

Application of diagrams in breeding work......................... 19

Production of fruit on secondary fruiting branches...................... 19

Influence of vegetative branches upon the shape of the plant............. 21

Effects of pruning on branch development......................... 22

Branch diversity in relation to environment........................ 24

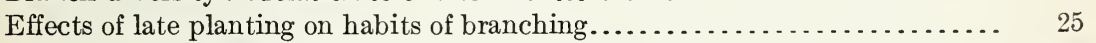

Abnormal vegetative growth on prostrate plants........................ 26

Branching habits of the different Egyptian varieties.................... 26

Conclusions.............................................. 27 


\section{LLUSTRATIONS.}

\section{PLATES.}

Page.

Plate I. Fig. 1.- Young Egyptian cotton plant denuded of leaves. Fig. 2.-Mature Egyptian cotton plant with excessive derelopment of limbs.

II. Fig. 1.-Mature Egyptian cotton plant with a number of mediumsized limbs. Fig. 2.-Mature Egyptian cotton plant with limbs

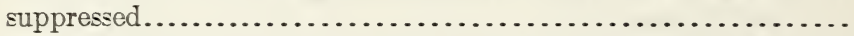

III. Diagrams of cotton plants of three varieties of acclimatized Mit Afifi

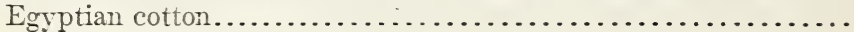

TEXT FIGURE.

Fig. 1. Diagram of an Egyptian cotton plant, showing the nature of branching in the Yuma rariety, an acclimatized strain 
B. P. I. -738 .

\section{THE BRANCHING HABITS OF EGYPTIAN COTTON.}

\section{INTRODUCTION.}

That the cotton plant produces two distinct types of branches which are variously developed in the different varieties and types of cotton and under different conditions of growth has been known for several years. The agricultural importance of these different habits of branching and the need of more careful study of such facts in relation to problems of breeding and acclimatization have been pointed out. ${ }^{1}$ The excessively large size of the vegetative branches on Egyptian cotton plants grown under irrigation in the Colorado River Valley in Arizona and California has necessitated a detailed study of these problems. Not only does this excessive vegetative growth occasion difficulties in cultivation and harvesting, but it causes the development of normal fruiting branches to be postponed. To place the growing of Egyptian cotton in the Southwest on a practical basis, cultural control of the production and development of regetative and fruiting branches must be established. A study of the branching habits of Egyptian cotton is necessary as a preliminary investigation of this problem.

The present paper gives the results of investigations of the branching habits of Egyptian cotton during the seasons of 1909 and 1910.

In 1909 one-acre plats of several important varieties were under observation at Somerton, in the Colorado River Valley, south of Yuma, Ariz., besides larger field plantings of two strains which have undergone several years of selectire breeding. Plats on the Pima Indian Reservation at Sacaton, Ariz., and near Los Angeles, Cal., including plantings of both imported and acclimatized seed, were also studied. The observations were made throughout the growing, fruiting, and mature stages of the plants. During the season of 1910 a series of Egyptian cottons planted throughout California and at Yuma and Sacaton in Arizona yielded corroborative evidence of the facts established in 1909.

1 Cook, O. F. Weevil-Resisting Adaptations of the Cotton Plant. Bulletin 88, Bureau of Plant Industry, U. S. Dept. of Agriculture. 1906. See also "Dimorphic Branches in Tropical Crop Plants: Cotton, Coffee, Cacao, the Central American Rubber Tree, and the Banana," Bulletir 198, Bureau of Plant Industry, U. S. Dept. of Agriculture. 1911. 


\section{TWO TYPES OF BRANCHES IN COTTON.}

The two kinds of branches of the cotton plant are distinguished as vegetative branches and fruiting branches. (PI. I, fig. 1.) Vegetative branches or "limbs" are borne either directly in the angle of the leaf with the stem (axillary position) or at one side or the other of the angle (extra-axillary position). Fruit-bearing branches occur only in the extra-axillary position and are called "fruiting branches." Vegetative branches are counterparts of the main stem in that they also bear branches, both vegetative and fruiting, which are distinguished as "secondary vegetative branches" (or "secondary limbs") and "secondary fruiting branches," respectively. In the present paper these terms will be used in conformity with these definitions.

\section{GENERAL CHARACTERS OF THE BRANCHING HABITS OF EGYPTIAN COTTON.}

Egyptian cotton plants, as grown in Arizona and southern California, produce a large number of limbs from the lower nodes of the main stalk. These limbs often attain nearly the size of the main stem or axis and are of more practical importance to the Egytian plant than to the Upland varieties. (Pl. I, fig. 2.) The latter also bear limbs at low nodes, but not in such numbers as the Egyptian types, and both limbs and fruiting branches often occur together at low nodes of the stem. In Egyptian cotton the large basal limbs are never accompanied by fruiting branches, i. e., the fruiting branches, which occur only in the extra-axillary position, do not arise in the Egyptian cottons from the same nodes which bear the large vegetatives. Because of this fact no fruiting branches occur on the Egyptian stalks until at a relatively high node, which varies with the variety and among individuals of the same variety. (Pl. I, fig. 2, and Pl. II, figs. 1 and 2.)

The axillary limbs which occur infrequently, and then only when paired at the same nodes with extra-axillary limbs or with lower fruiting branches, are small and of relatively little importance. Because the vegetative and fruiting branches are thus to be found almost isolated one from the other on the stem, a fairly distinct condition of branch zones prevails in all Egyptian cotton plants.

THREE BRANCH ZONES IN THE EGYPTIAN COTTON PLANT. ZONE OF VEGETATIVE BRANCHES (NODES 3 TO 10).

The Egyptian cotton plant may be divided into three branch zones. The position of these zones is graphically shown in figure 1. The zone of vegetative branches includes the first 10 nodes at the 


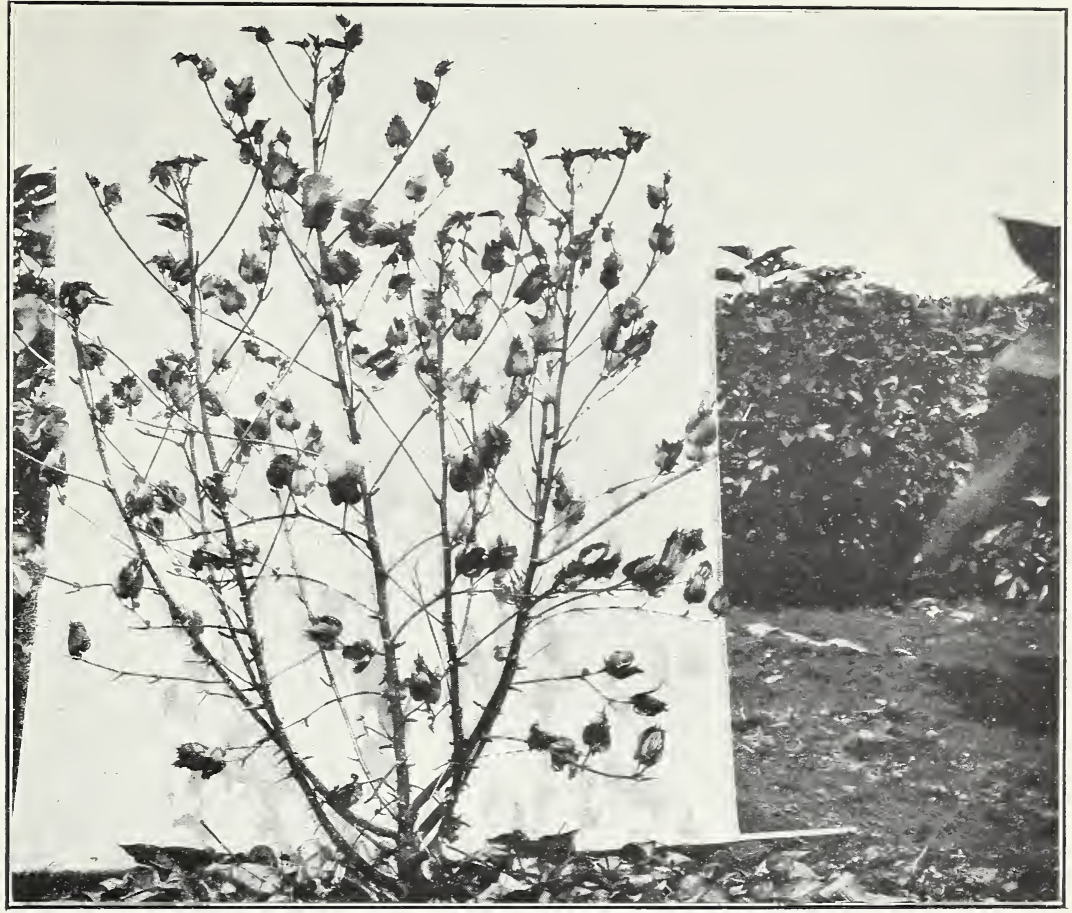

Fig. 1.-Young Egyptian Cotton Plant denuded of Leaves, Showing Large LIMBS ARISING at THE Base of THE STEM AND SLENDER FRUITING BRANCHes FROM LOCATIONS HIGHER ON THE STEM. SECONDARY FRUITING BRANCHES BORNE BY THE LIMBS ARE ALSO SHOWN.

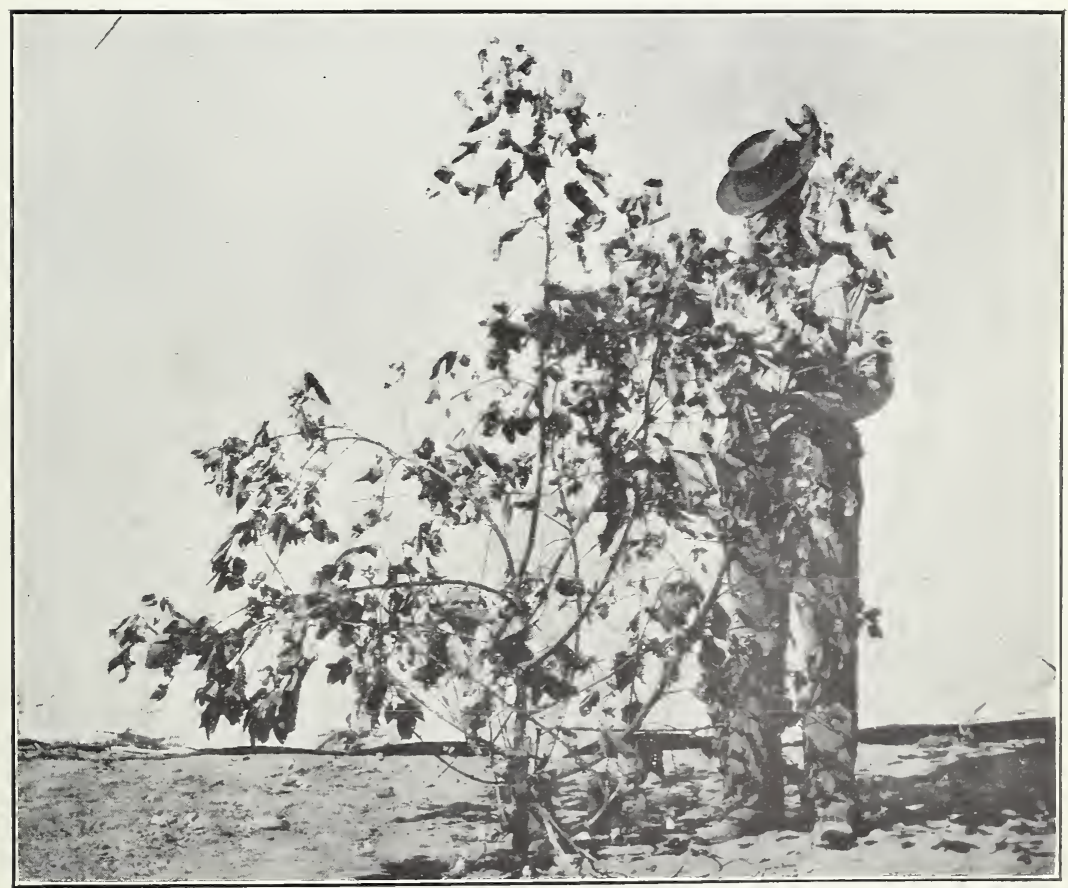

Fig. 2.- Mature Egyptian Cotton Plant with Excessive Development of Limbs. 


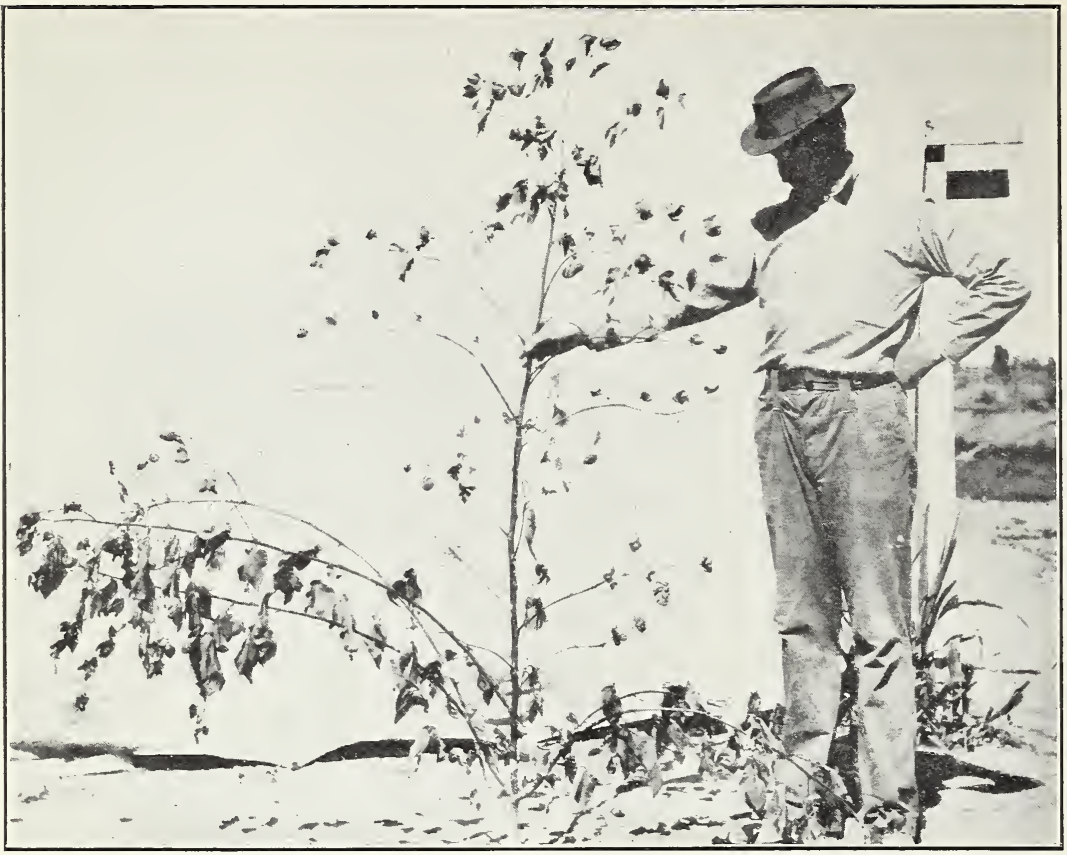

Fig. 1.- Mature Egyptian Cotton Plant with a Number of Medium-Sized LIMBS, SHOWING DIFFERENCE IN SIZE AND POSITION OF LIMBS AND FRUITING Branches. The long Branches at the Base of the Plant are limbs; the SHORTER BRANCHES APPEARING JUST ABOVE THE LIMBS AND CONTINUING TO THE TOP OF THE STEM ARE FRUITING BRANCHES.

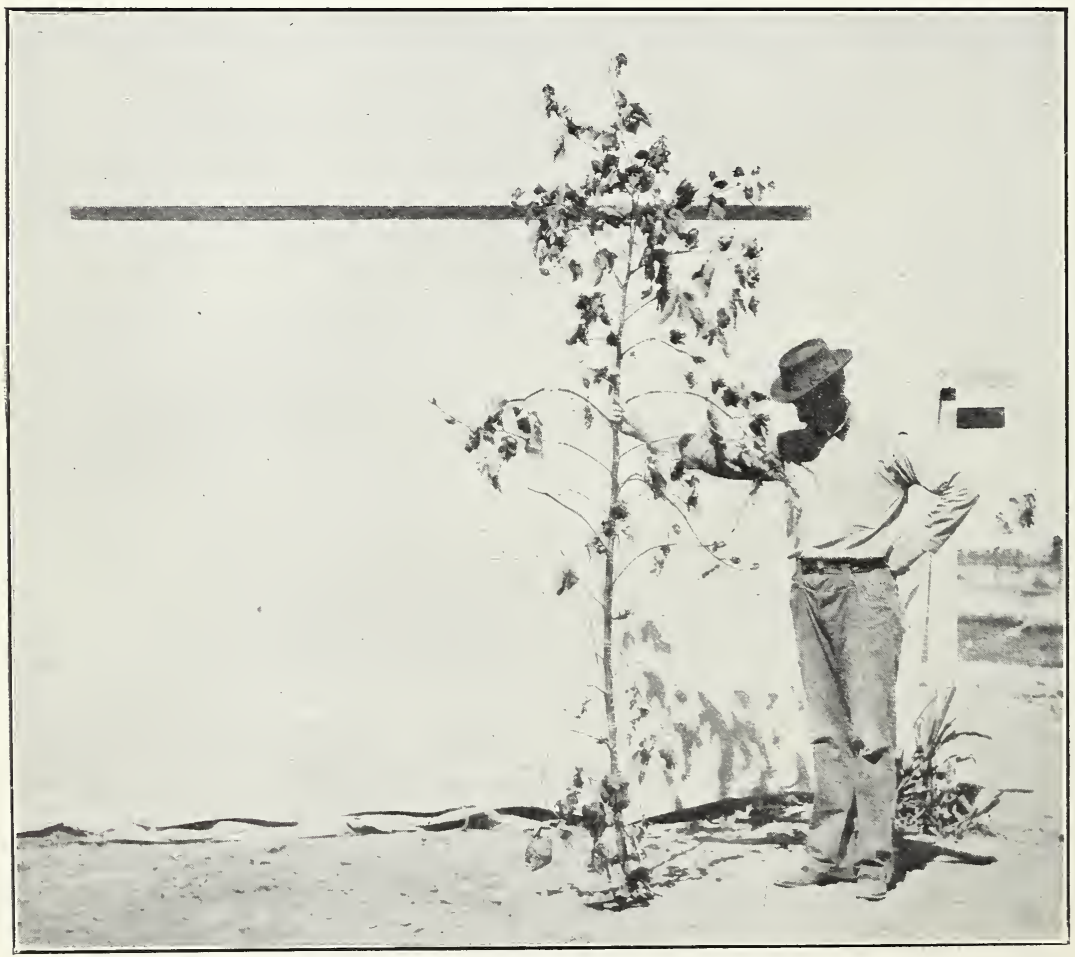

Fig. 2.-Mature Egyptian Cotton Plant with Limbs Suppressed. 
base of the stalk, which usually produce from 6 to 10 limbs. The extent of this zone varies in different individuals. Limbs may develop as high as the twelfth or even the fourteenth node, but this is rather an extreme limit.

\section{ZONE OF RUDIMENTARY BRANCHES, OR TRANSITION ZONE.}

Between the limbs and the fruiting branches there are usually two or three nodes at which the buds remain dormant, or the branches

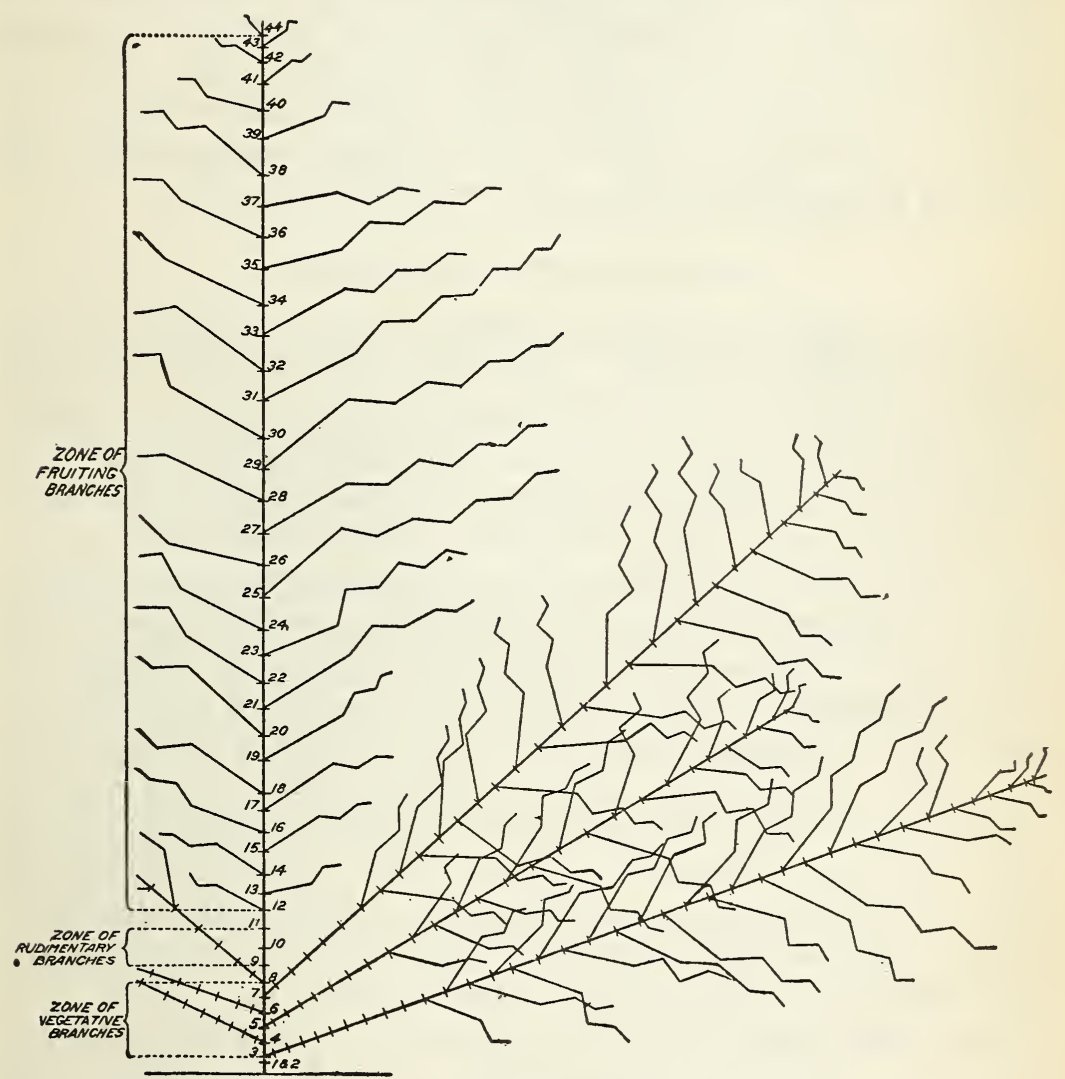

Fig. 1.-Diagram of an Egyptian cotton plant, showing the nature of branching in the Yuma variety, an acclimatized strain. The perpendicular line represents the axis which bear's vegetative branches or limbs (straight lines) and fruiting branches (zigzag lines); the zigzag lines arising from the limbs are the secondary fruiting branches. The zone of rudimentary branches is indicated at three nodes between the limbs and the fruiting branches. The nodes of the axis are numbered.

are extremely short or abortive. For convenient reference, this region is termed the zone of rudimentary branches. . It is not uncommon to find in this zone fruiting branches, a few inches in length, with all flower buds absorbed, sometimes accompanied by an abortive or abnormal axillary limb. This portion of the stem may be looked 
on as the zone of transition from the vegetative to the fruiting condition. Infrequently a large limb occurs at a node above this transition zone.

In this zone of undeveloped branches many irregularities occur, indicative of the transition state of the branches. One of the plants, which was carefully measured during the spring of 1909, had the position of the fruiting branch and limb reversed at successive nodes in this zone. An abortive fruiting branch at node 9 was borne on the left of the leaf axil; the axillary limb at the same node was growing rapidly. At all succeeding nodes the relation was reversed, the fruiting branch being on the right side of the axil. At a later stage in the growth of this plant the axillary limb at node 9 was found to be abnormal, while the extra-axillary branch at this node remained abortive, as was the axillary branch at node 10 .

\section{ZONE OF FRUITING BRANCHES.}

The first fruiting branches are borne at nodes directly above the zone of undeveloped branches. On many plants the first few fruiting branches may be short, with flowers abortive and the branches determinate after one or two branch nodes have been formed. These branches are very slender and weak. The zone of developed fruiting branches usually begins at or near the thirteenth node and extends to the top of the plant, each node normally bearing a fruiting branch. The fertile zone may be divided into two subzones. At the nodes which produce the first fruiting branches the axillary bud may be developed into a slender limb. The number of nodes at which this occurs is restricted, only a few nodes bearing a fruiting branch and a limb. As discussed later, the small axillary limbs occurring with fruiting branches are apparently of different character from the large limbs lower on the plant. Above where limbs occur at the same node with fruiting branches, short axillary branches are often dereloped in addition to the regular fruiting branches. These resemble short fruiting branches and bear one or two flowers.

It has been suggested that this apparently axillary fruiting branch represents a secondary fruiting branch borne by the axillary limb, which is itself suppressed, but which sometimes appears to be represented by a very small bud at the base of this seemingly axillary fruiting branch. An alternative explanation, which may be justified by the apparent mutability of the branch types in Egyptian cotton, is that there has been a complete transformation in some cases from the axillary limb to an axillary fruiting branch. It has been observed that the flower of one of these apparently axillary fruiting branches sometimes blooms as early as the day following the flower at the first node of the accompanying fruiting branch. 
These fruiting branches which occur in the axillary position often grow from the side of the base of the regular fruiting branch, a condition which may represent a partial fasciation, though the small fruiting branch appears to be borne by the larger branch. These axillary branches are always short, the terminal vegetative bud aborting after one or two squares have been set. At the lowest nodes where such branches appear they normally bear a leaf opposite the flower bud, but at higher nodes the leaf may be abortive and the branch appear as a very long flower stem borne directly on the main stalk of the plant. The axillary branches usually abort and drop off at most of the nodes while in the condition of very small buds, but, nevertheless, the buds are formed with regularity on both main stem and limbs. In an acclimatized stock of Egyptian cotton grown at Somerton, Ariz., the axillary buds were retained at some of the nodes where they first appeared, aborted at from 15 to 20 nodes above this, leaving well-defined scars, but were again retained at the top of the main axis and limbs, and more constantly than where they first appeared lower on the stem. This was observed late in October on plants which were 8 to 10 feet tall, with 40 to 46 nodes, and still growing.

\section{REGULAR SEQUENCE OF BRANCH DEVELOPMENT IN EGYPTIAN COTTON.}

Buds occur in all leaf axils, including those of the cotyledons or seed leaves. For convenience, the nodes of the main axis may be numbered from the base of the plant with the nodes of the cotyledons considered as the first two nodes, the first true leaf coming from the third node. This does not seem illogical, since one of the cotyledons usually stands slightly higher than the other. There is generally a regular sequence of branch development from the lower nodes upward.

Under some conditions limbs may grow from buds in the axils of cotyledons. At Glendale, Cal., in 1910, 30 plants grown from imported Mit Afifi seed bore limbs at 42 of the 60 nodes of the cotyledons; in many cases buds at both of the cotyledon nodes of a plant developed. A row of 30 plants of the acclimatized Yuma variety ${ }^{1}$ bore 39 limbs at the 60 nodes of the cotyledons.

Branches usually do not begin to develop until from 6 to 10 true leaves have appeared on the main stem, though exceptions occur when the plants in a row are thinned very early, and are thus given more space for lateral growth. There are also individual differences in this regard, some plants deferring the development of branches

\footnotetext{
1 The Yuma variety was originated by Mr. T. H. Kearney from stock derived from imported Mit Affi Egyptian seed. A detailed account of the origin and development of this variety can be found in Bulletin 200 of the Bureau of Plant Industry, entitled "Breeding New Types of Egyptian Cotton," p. 13 et seq. 
much longer than others. Though the branch buds appear when the accompanying leaves are yet small, they usually remain dormant for a considerable period.

On May 11, 1910, nearly two months after planting, a census of 550 of the most forward plants, bearing 6 to 8 leaves, showed the largest branches to be less than an inch in length. In this case the derelopment of the plants was somewhat retarded by cool weather, though later plantings, which had all the warmth necessary for rapid growth, exhibited a similar dormancy of buds.

Within the lower or vegetative zone an absolute sequence of position and size of branches does not obtain. It is usual for some of the lower nodes to remain permanently dormant, so that only five or six branches commonly develop from the first 8 or 10 nodes of the plant. Of the limbs that do develop, the lowest is not necessarily the largest. In 28 per cent of the 550 plants already referred to the largest early branch was at the third node, in 28 per cent at the fourth node, and in 26 per cent at the fifth node. In the remaining 18 per cent of the plants there was no noticeable difference between the size of the branches at the third, fourth, and fifth nodes. A few cases have also been observed where the largest early branch was at the sixth node.

In the zone of fruiting branches, however, a more uniform development is observed. Here, with the exception of the first few nodes, at which buds may be dormant or where the fruiting branches may be abortive or have a determinate growth, each node usually produces a fruiting branch with regularity. Dormant branch buds are uncommon in the upper part of the plant.

In the branches of young plants a general sequence of diminishing size obtains from the base of the plant to the top, so that the first fruiting branch, which may occur at node 12, is in regular order shorter than the limb at the node next below. In older plants the greater development of limbs and the accidents of abortion obscure this regular sequence of size.

\section{DISTINCTION BETWEEN FRUITING AND VEGETATIVE BRANCHES.}

The chief distinction between fruiting and vegetative branches is that fruiting branches bear a flower bud at each node opposite the leaf, while limbs bear no flower buds. By this character fruiting branches are early distinguishable from limbs, the first small flower bud or square of the fruiting branch being apparent about as soon as the first leaf of the young branch begins to unfold.

The limbs at nodes below the first fruiting branch grow to great length, developing sometimes as many as 50 nodes and occasionally attaining a length equal to that of the main stem. In contrast to 
these, the mature fruiting branches seldom have more than 12 nodes, usually only 6 or 8 , and are proportionately shorter than the limbs.

Unlike the vegetative limbs, the first internode of the fruiting branch grows very rapidly and reaches almost its full length before the second internode begins to grow. This first internode is often three or four times as long as the basal internode of limbs on the same plant. Because of this the distinction between fruiting branches and limbs is much more apparent in Egyptian cotton than in Upland cotton, where the internodes of all branches are more nearly of the same length. Although the first internode of fruiting branches of Egyptian cotton is usually from 6 to 8 inches in length, great variations, due to locality and cultural conditions, have been noted and are discussed later.

A minor distinction between limbs and fruiting branches in young plants is the wider angle with the stem that is made by the fruiting branches. As the branches grow and become heavier this difference becomes more obvious. The angle which the limbs form with the stem increases as their weight increases, but their rigidity exceeds that of the fruiting branches and maintains them at a comparatively acute angle with the stem. The mature fruiting branches, which are slender and comparatively more heavily laden, assume an even wider angle with the stem and finally become pendent, in some cases almost vinelike in appearance.

\section{FRUITING BRANCHES REPLACED BY VEGETATIVE BRANCHES.}

A limb may take the place of a fruiting branch, not only in the lower part of the plant but even at nodes above those that have begun to develop normal fruiting branches. Such replacements of fruiting branches by vegetative branches usually occur at the first or second node above the first fruiting branch. These vegetative branches develop after the fruiting branches below and before those above and in the regular extra-axillary position of fruiting branches, thus appearing to belong to the regular sequence of the branching system. Nevertheless they behave as true limbs, lacking the long first internode and the flower buds which characterize fruiting branches. Out of 30 plants taken at random in a field planted to an acclimatized stock of an Egyptian strain (Yuma variety) two plants were found to exhibit this phenomenon. In 1910 a conjugate hybrid plant between Mit Afifi Egyptian and Triumph cotton (a shortstaple American Upland) in which the first fruiting branch appeared at node 12 bore an extra-axillary limb at node 13 and another at node 14. Fruiting branches were borne at node 15 and at all succeeding nodes. 


\section{TRANSFORMATION OF FRUITING BRANCHES INTO VEGETATIVE BRANCHES.}

Branches which began their derelopment as fruiting branches often appear to change to limbs, even after producing buds at the first or second node. The flower buds on such branches are seldom, if ever, matured. Branches of this intermediate form are rather common and usually occur at the first few nodes in the zone of fruiting branches. Among 10 plants of an upright type grown from imported Mit Afifi seed 6 bore branches of this nature, all of which were confined to the first $t$ fruiting-branch nodes of the stem. Two of these transformed branches occurred just below the first normal fruiting branch, 3 just above it, and 1 each abore the second and the third fruiting branches.

Another intermediate form of branch has no flower buds, though the first node grows rerr long, as in the typical fruiting branch. Analogies between these abnormal intermediate forms of branches and sterile hybrids have been pointed out by $\mathrm{Mr}$. Cook in his discussion of branching in tropical crop plants. ${ }^{1}$

These "hybrid" branches often are to be recognized by their larger diameter and greater length. They usually take on the regetatire habit of limbs, becoming much stronger and more rigid than fruiting branches. Sereral branches of this class occurred as high as the twentieth or twenty-fifth node in Mit Afifi plants grown from imported seed, their exceptional nature being apparent from their sharp contrast in size with the fruiting branches at nodes abore and below. They were three times as thick at the base as the fruiting branches and areraged 18 nodes to the branch. They were still growing, while the fruiting branches had only six or seven nodes and were determinate, the apical bud having aborted. These transformed branches retained the pendent form of fruiting branches, though fruit was borne only at the first node or two. The remainder of the branch gare no indication, even by the presence of a scar, that it was fertile beyond these first two nodes.

\section{HOMOLOGY BETWEEN LARGE BASAL IIMBS AND FRUITING BRANCHES.}

In the Egrptian cotton plant the large basal limbs in the zone of regetative branches appear homologous to the fruiting branches of the main stem rather than to the small limbs which occur higher on the plant in the zone of fruiting branches. As preriously stated. a large lower limb and a fruiting branch are nerer found at the same node in Egyptian cotton; the small upper limbs, which are axillary;

\footnotetext{
1 Cook, O. F. Dimorphic Branches in Tropical Crop Plants: Cotton, Coffee, Cacao, the Central American Rubber Tree, and the Banana. Bulletin 198, Bureau of Plant Industr5, U. S. Dept. of Agriculture, 1911, p. 24.
} 
occur only with fruiting branches or very infrequently with large limbs. While the earliest lower limbs appear to arise from the axil of the leaf, limbs at later nodes in the zone of vegetative branches become more and more displaced from the axil, so that those in the upper limits of this zone can be seen to arise outside the axil and on the same side of the axil as the fruiting branches at nodes just above. This can be seen most readily in young plants while the limbs are small. On the other hand, the position of the small upper limbs is unquestionably axillary. Cases have already been cited of large extraaxillary limbs at nodes above those bearing the earliest fruiting branches, but unaccompanied by fruiting branches at the same nodes. In such cases it is apparent that the limb replaces a fruiting branch and is evidently of the same nature as the lower limbs. Furthermore, under some conditions fruiting branches which are always extraaxillary are found among the lower limbs, being borne at very low nodes (6-8) in a stock of Egyptian cotton which usually bears large limbs at these low nodes; in such instances no large limbs accompanied these low fruiting branches.

That the large limbs of the zone of vegetative branches are not homologous to the limbs outside this zone is shown by the further fact that the latter, though sometimes long, are usually slender and weak and bear secondary fruiting branches only at very late nodes, while the lower limbs are robust and bear secondary fruiting branches at comparatively early nodes.

\section{ABORTION OF FRUITING BRANCHES.}

The lower fruiting branches often abort the terminal bud after setting one or two bolls, and even these bolls may be poorly nourished and consequently undersized. A few of the early fruiting branches may retain no fruit at all. This may be brought about by the appropriation of moisture for the luxuriant and rapid growth which the plant makes after these first fruiting branches are put forth. It was noticed that plants in the sandy part of the field at Somerton, Ariz., in 1909, aborted their leaf buds on all fruiting branches. In other parts of the same field, where the soil did not dry out so rapidly, no such blasting of the leaf buds took place. The plants growing in sandy soil had thus ceased to produce new bolls at a period when fruiting branches in other parts of the field were growing normally and fruiting was uninterrupted. Overshading of the lower fruiting branches has been suggested as a possible explanation of their frequent failure to develop normally, but the shading is not necessarily greater than in Upland varieties, where the lowest fruiting branches are generally the most heavily laden. In Egyptian cotton this is seldom the case. 
IMPORTANCE OF SELECTION FOR LOW FRUITING BRANCHES ON THE IIAIN AXIS.

Selection for low-fruiting branches may be a practical means of increasing the yield and earliness of Egyptian cotton. It was found that one of the most productive of the acclimatized stocks consistently bore fruiting branches lower on the stem than any other stock of Egyptian cotton being grown at Sacaton, Ariz., in 1910. This stock was from a selection made at Sacaton in 1909 by Mr. E. WT. Hudson, of the Bureau of Plant Industry. Some superiority over imported stocks is shown by other selected strains in their habit of developing fruiting branches at low nodes of the stem, though the strains were not selected originally for low-fruiting branches. That a larger yielding type can be secured in this way without affecting the quality of the fiber seems probable, as the fiber in the Egyptian cotton, the Yuma variety in particular, holds up in quality and length remarkably well under the various conditions which occasion the dirersities in branching.

In plantings from imported seed of Egyptian varieties in Arizona and California considerable diversity has existed as to the height on the stem of the first fruiting branch. Nubari, a new variety, planted in the United States for the first time in the season of 1909, has behaved more like the acclimatized stocks and gives good promise of rapid adjustment to conditions in the southwestern United States. From what is known in regard to close planting in Egyptian field culture, it seems likely that the Egyptian cotton has never received selection for the development of low-fruiting branches. Close planting, which would almost preclude selection of any sort, would also naturally tend to suppress the lower-fruiting branches. The assumption that low fruiting-the development of the early fruiting-branch buds and the retention of a large percentage of flower buds-is the normal habit of the plant seems reasonable, since, in all plantings which have been observed, plants have made the attempt, as it were, to fruit at low nodes by putting out abortive fruiting-branch buds. Occasionally, even the zone of undeveloped branches previously described is eliminated by the development of the fruiting-branch buds at every node.

\section{REPRESENTATION OF BRANCHING HABITS BY DIAGRAMS.}

By means of the accompanying series of diagrams (Pl. III), which are reproduced from exact copies of diagrams taken in the field, it has been possible to show the difference in the amount of fruiting on the primarv fruiting branches of various strains of acclimatized 


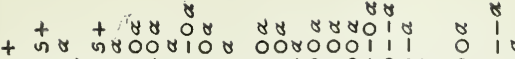

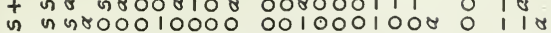

$\operatorname{ten} 00000100010800000010110101000$

$2 \sin 11,010000000100111101001011010$ is

20000000111100000110011001001111101,80

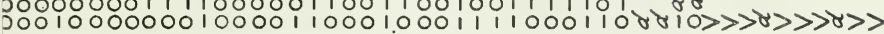

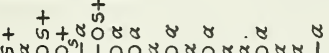

$\forall \gamma$

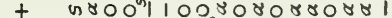

$\operatorname{tin} \pi 00100000000100000$

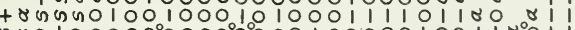

$++200101010011000000000000001110001$

++1 no0100000000000010010011001010011 is

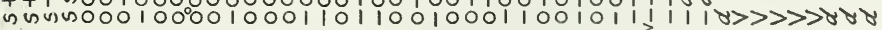

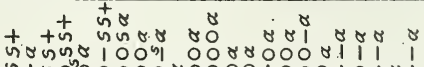

nangता

$++a+n / 2, \pi, 0.00000000100010101$

+ Innn 1001010000100101001011

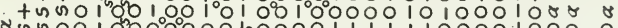

$+8 n n 0010_{0} 0.000180000111111000010000$

tnno no $000000000000000100000000111111 \quad a 00$

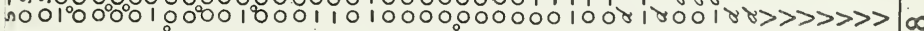

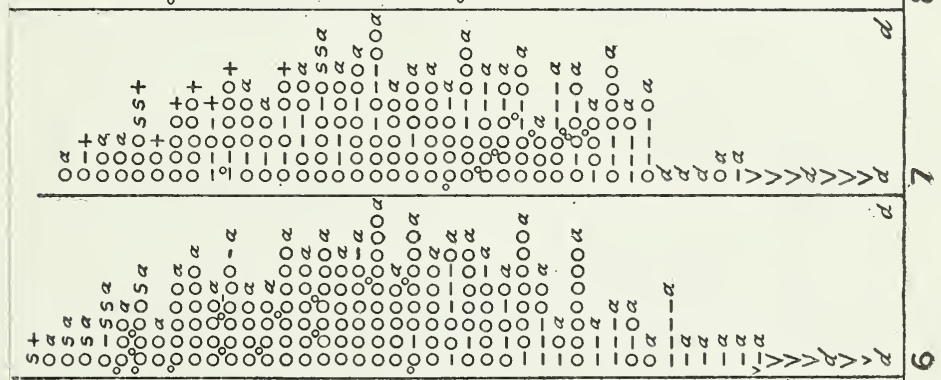

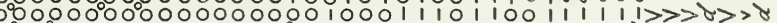

$+\theta+\theta$

8 encino

$++\infty$ nnoooo

unino 10001

$+\theta \cos 000000000$

$\operatorname{tin} n=1,10000000$

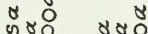

n)

$0.00 \pi$ oborisis

o.

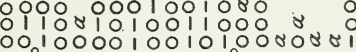

$000000001001 \% 000001$

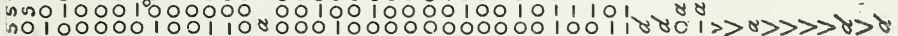

$\checkmark$
$=$

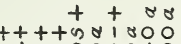

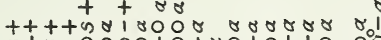

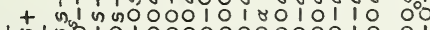
$++n+n d 10100000000000100180 \pi$, + no00001.000.10110001011 1011,1000 $+\theta+\omega+n 000000000 \% 1010100000001100010$

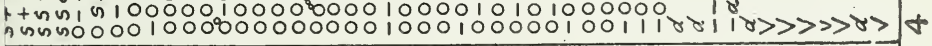

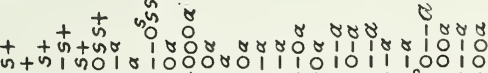
$+\theta+t a 1000001111000001100110010180$ nununsio 101000100100101100100001000 onnnnan $10101000100100101100100001000 \%$ ก1 $1000001010000000100100000000010,1800101>\forall>>>>\theta$

$$
++\theta \alpha \theta \theta \sin \theta
$$

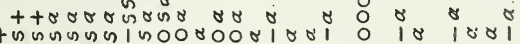

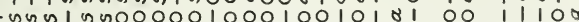
10001
100000 tnnnanol

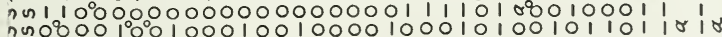

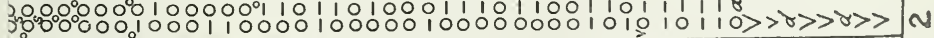

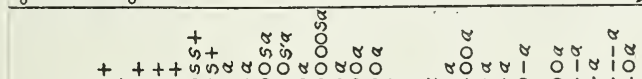

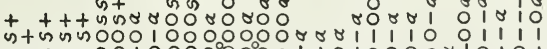

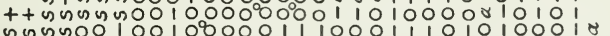

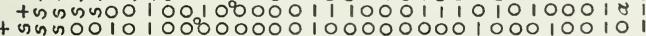
n $10001000001000000000000010110001111 \pi 848$ nn"no00 $100000001000011010000001100000100111 \gg>>\forall \forall \forall$ 


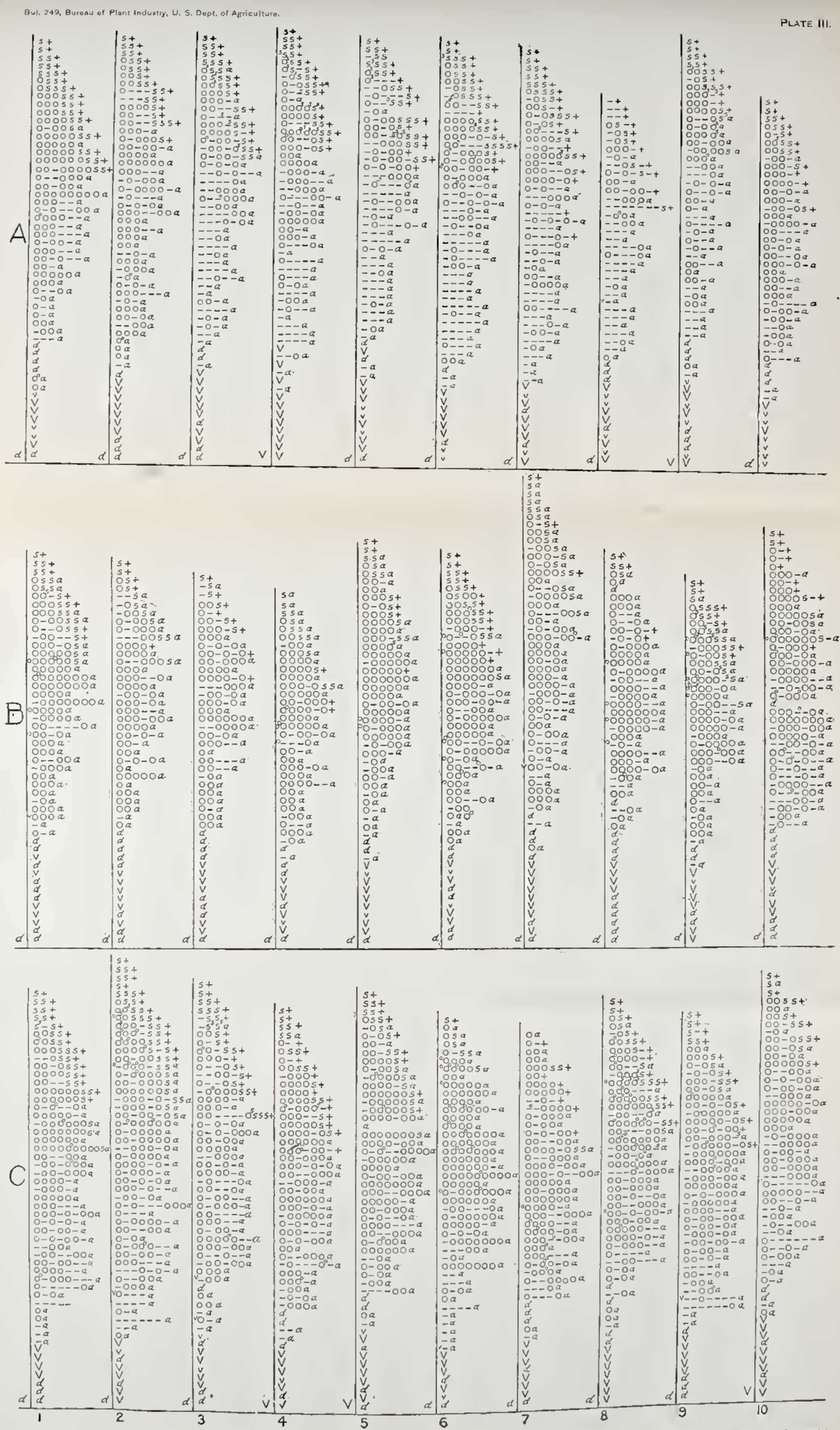

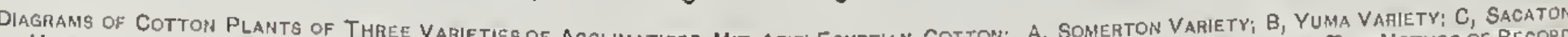

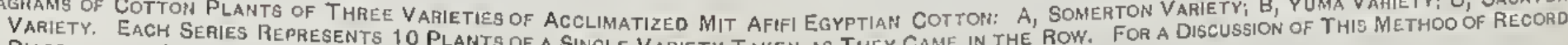

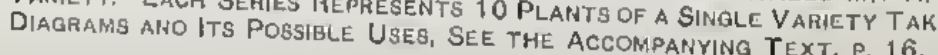



Egyptian cotton. Each series is composed of the diagrams of 10 plants of a single strain, taken as they came in the row.

Explanation of the diagrams.-The perpendicular line represents the axis of the plant; the letter $d$ designates a dormant bud; large $V$, a large limb or vegetative branch; small $v$, a small limb. The letter $o$ indicates a node of a fruiting branch bearing a boll; the letter $s$ indicates a square or bud at a node of a fruiting branch, while a dash (-) represents a node of a fruiting branch from which the bud or the boll has been shed. The small $a$ at the end of a series of these three last-mentioned characters means the abortion of the leaf bud and the termination of the growth of the branch, while the plus sign $(+)$ signifies that the branch is still growing. The small $o$ just at the right of the perpendicular and slightly above the line of the fruiting branch indicates fruits borne on fruiting branches in the axillary position. Occasionally two or more fruits are borne by such branches. A small $o$ above and to the right of a character designating a node of the fruiting branch represents the fruit borne on a secondary branch in the axillary position at this node of the fruiting branch.

The signs were placed to the right of the axis to facilitate the work in the field. This plan has prored even more instructive than a diagram with successive branches placed alternately on the two sides of the axis, as the diagraming of all the branches on one side provides more ready means of comparison and shows more clearly the variation in determinateness of the fruiting branches. Each node of the axis is indicated by a character or series of characters at the right of the perpendicular line. Each fruiting branch is built of $o$ 's and dashes (-), the number of nodes of a fruiting branch corresponding to the number of these characters in a series to the right of the perpendicular line. At the base of each plant the two opposite characters indicate the two nodes of the cotyledons, which are practically opposite and are counted as nodes 1 and 2 of the plant.

The general similarity between the shape of the diagrams in each series indicates the close relationship of the plants. Marked differences in a diagram, as in the case of plant No. 7 in series B, usually indicate diversity in many particulars. In this instance the bolls of plant No. 7 were small and the fiber was poor. Comparison of each series of 10 diagrams with the others affords a conception of the differences existing between strains, in height of first fruiting branch, number of fruiting nodes on fruiting branches, amount of fruit retained, involving the earliness of the strains, the number and size of the limbs, and the height of the plant. One inch of the perpendicular line represents approximately 1 foot 9 inches. 
CHARACTERISTICS OF THE FRUITING HABITS OF DIFFERENT ACCLIMATIZED STRAINS OF EGYPTIAN COTTON SHOWN BY THE DIAGRAMS.

The space between the perpendicular line (axis) and a curve extending through the tips of the horizontal series of characters (fruiting branches) from near the base of the perpendicular to its apex represents the fruiting area provided by the fruiting branches of the main axis. The actual amount of fruit retained is shown by the frequency of the letter $o$. As the perpendiculars are all equidistant, the difference in the amount and contour of unoccupied space between the parallel perpendiculars shows most strikingly the individuality of each variety.

From the diagrams it can be seen that the Somerton variety puts out its fruiting branches at low nodes of the axis, but that a large proportion of the fruit is shed, the dashes appearing frequently. This variety also appears to have a less determinate growth than either of the other varieties and would be most prolific under cultivation that would permit the retention of all the bolls.

The Yuma variety retains a larger percentage of fruit than the Somerton variety, but it has a smaller fruiting area, mainly because of its shorter fruiting branches. This variety has a tendency to limit the length of its fruiting branches to six nodes, though plant No. 10 of the Yuma series, it will be seen, is an exception to this rule in that the fruiting branches are consistently seven nodes long. From the standpoint of crop production the Yuma variety has thus far proved the most promising. More extensive plantings of the other two varieties may prove them to be of equal or even greater value.

The Sacaton variety, as shown by the diagrams, behaves most consistently in putting out normal fruiting branches at nodes 11 and 12 and in retaining a large proportion of the fruit. The fruiting area is also larger than in the other two varieties, both on account of its longer fruiting branches and its habit of growth, which, like the Somerton, is less determinate than that of the Yuma variety. This selection yields heavier than either of the other varieties, but has been tested only in small plats.

The fruit production by secondary fruiting branches of the limbs has been disregarded in these diagrams. The similarity between the habits of the large limbs and axis, discussed later, is such that the retention of fruit on secondary fruiting branches of the limbs corresponds to that of the fruiting branches of the axis in each variety. Thus the large limbs do not influence the relative fruitfulness of a variety except as they are appreciably more numerous or fewer. As far as field conditions are concerned, a study of the main axis of the 
plant answers all purposes, for closer planting, which will be practiced under field conditions, will equalize the total fruiting area of few-limbed and many-limbed plants by curtailing the growth of limbs.

\section{APPLICATION OF DIAGRAIIS IN BREEDING WORK.}

Plant diagrams like those here used afford a simple means of recording graphically the fruiting habits of strains of cotton from year to year. They do not represent the comprehensive knowledge gained of each strain by study and comparison of many individuals throughout the year, but they do offer a means of representing graphically and statistically differences and similarities that exist among different varieties and different individuals within the same variety. Mistakes are also less common where the data are recorded graphically instead of in figures. If so desired, the material contained in the diagrams can be used to calculate correlations and statistical constants.

Kept through a series of years, these diagrams will equal in value as breeding records the more elaborate statistical methods of recording the expression of characters, for most of the data regarding vegetative behavior and fruiting habits are expressed in such diagrams. Records of this kind should be valuable in the study of the problems of heredity and variation, and if kept on a series of irrigation or cultural experiments they would provide useful data for determining the effect of different methods of culture.

\section{PRODUCTION OF FRUIT ON SECONDARY FRUITING BRANCHES.}

Under conditions of very luxuriant growth, as in most of the Arizona experiments, the fruiting branches of the main axis bear only about one-third of the fruit produced by the plant. The remainder of the fruit is borne by the secondary fruiting branches of the large limbs. On August 1, 1909, a count of 6,981 bolls on 52 plants in a block of acclimatized Egyptian cotton showed that only 36.6 per cent were borne on fruiting branches of the axis, the remaining 63.4 per cent being on the secondary fruiting branches. The fruit borne by these large branches develops considerably later than that of the main axis, usually producing the bulk of.the second picking. The first fruiting.branch bud does not appear on the lower limbs jefore the sixth to eighth node of the limb, and often no secondary fruiting branch is retained until several nodes beyond this, as . the early secondary fruiting branches may be abortive. Thus a similar mode of developing the fruiting branches occurs on both the main axis and the vegetative branches. The secondary fruiting branches are, as a rule, the only branches to develop on limbs; such secondary 
limbs as do develop occur at the low nodes of the large limbs and remain dormant until the secondary fruiting branches have appeared. In this respect the limbs differ from the main axis.

Secondary fruiting branches appear at successively lower nodes on the limbs the higher the position of the latter on the axis. For instance, on the youngest limb of the plant in the zone of vegetative branches the first secondary fruiting branch may be borne at the fourth node, while on the oldest limb the first secondary branch is seldom developed before the tenth node. This is shown in graphic form in Table I. The data here presented represent the averages from 15 plants of each stock and were taken on mature plants at Somerton in the fall of 1909.

TABLE I.-Nodes at which secondary fruiting branches arise on vegetative branches.

\begin{tabular}{|c|c|c|c|c|}
\hline \multirow{3}{*}{ Limbs. } & \multicolumn{4}{|c|}{ Variety observed. } \\
\hline & \multirow{2}{*}{$\begin{array}{l}\text { Yuma ac- } \\
\text { climatized. }\end{array}$} & \multicolumn{2}{|c|}{ Mit Afifi imported. } & \multirow{2}{*}{$\begin{array}{l}\text { Jannovitch } \\
\text { imported. }\end{array}$} \\
\hline & & $\begin{array}{c}\text { Ordinary } \\
\text { type. }\end{array}$ & $\begin{array}{c}\text { Infertile } \\
\text { type. }\end{array}$ & \\
\hline 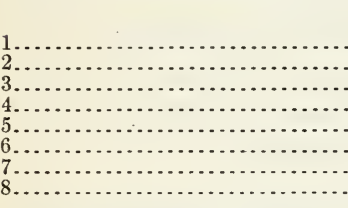 & $\begin{array}{r}\text { Node. } \\
10 \\
8 \\
8 \\
7 \\
6 \\
6 \\
5\end{array}$ & $\begin{aligned} & \text { Node. } \\
& 10 \\
& 8 \\
& 6 \\
& 6 \\
& 6 \\
& 6 \\
& 5 \\
& 4\end{aligned}$ & $\begin{array}{l}\text { Node. } \\
16 \\
15 \\
19 \\
12 \\
11 \\
10 \\
11 \\
10\end{array}$ & $\begin{aligned} & \text { Node. } \\
& 10 \\
& 8 \\
& 8 \\
& 7 \\
& 6 \\
& 6 \\
& 6 \\
& 5 \\
& . . . . . .\end{aligned}$ \\
\hline
\end{tabular}

1 These data represent averages from 15 plants of each stock.

In Table I, limb 1 represents the oldest (lowest) branch on the plant; limb 8 is the youngest (highest) limb in the zone of vegetative branches. It is evident that the younger limbs bear their secondary fruiting branches at successively lower nodes, so that limb $\delta$ bears its first fruiting branch at node 4 , though limb 1 does not retain a fruiting branch until node 10. The table further shows that acclimatized and unacclimatized (newly imported) stocks of Egyptian cotton bear fruiting branches at practically the same height on their corresponding limbs. The variability of fruiting branches of the main axis is considerable in the same stock and is still greater when imported and acclimatized stocks are compared. Selection for low fruiting branches of the axis gives more promise of results than does selection for low fruiting branches of the limbs.

On those axillary limbs which infrequently develop at the same nodes of the axis with the primary fruiting branches the arrangement of secondary fruiting branches, as observed on the large lower 
limbs, does not hold. On the axillary limbs the normal secondary fruiting branches, instead of being borne at nodes near the axis, are deferred until very late nodes.

Rejection of fruiting-branch buds on the lower limbs appears to be a constant habit, the buds pushing out and then becoming atrophied at from two to six nodes below the first node at which a fruiting branch is retained.

The production of very late secondary fruiting branches is correlated with the slender erect habit of the infertile plants, which appeared rather infrequently in imported Mit Afifi in 1909. Such a phenomenon may be an indication either of reversion or of hybridization. Some cases of unusual fertility may likewise be accounted marks of hybridization. Extreme fertility marks the early generations of a hybrid, while there is a tendency to sterility in later generations. On very fruitful hybrid plants the same ratio as in pure Egyptian types existed between the amount of fruit borne by the limbs and that borne by the main axis, about two-thirds of the total crop being found on the limbs.

\section{INFLUENCE OF VEGETATIVE BRANCHES UPON THE SHAPE OF THE PLANT.}

As shown in the preceding discussion there is variation in the position and degree of development of the fruiting branches. Though this is often well marked, it is not the most conspicuous kind of variation in the branches. Variations in the limbs have more effect upon the shape of the plant. The number of large limbs, their length, and the angle which they form with the main axis are all factors that determine whether the plant is of a bushy shape or is strictly erect, with a prominent leading axis.

It sometimes occurs that the limbs are not developed at all, in which case the plant is a single stalk with horizontal or drooping fruiting branches. This limbless condition is not frequent. Indeed, plants are more often found with the limbs so strongly developed that it is difficult to distinguish the main axis among them. The extent to which a limb may take the place of the main axis has been observed in plants that have been topped just above the fourth or fifth node, thus forcing the development of the lower limbs. In plants that mature after such pruning the limb from the last node below the severed axis has taken on the functions and appearance of the main axis so completely that the shape of the matured plant is perfectly normal and the abnormality can be distinguished only by the closest inspection. It sometimes appears, even in unpruned plants, that the limbs have usurped the leading functions of the axis, and have appropriated the nourishment to themselves, leaving the axis weak, while they are robust and of large diameter. 
A common type in newly imported stocks of Mit Afifi grown in 1909 was a strict, upright plant, with more or less rigid axis and limbs ascending at sharp angles, so close to and so nearly parallel with the axis that the fruiting branches of the main axis occasionally extended beyond the limbs.

Plants bearing more numerous low limbs are necessarily of greater diameter and more bushy; the lowest limbs arise from the axis at broad angles and extend out farther from the axis than the upper branches. The limbs usually reach nearly the height of the main axis, unless they.are weighted down with fruit, in which case they spread more widely and leave the axis free and overtopping them. The latter is the condition in the most fruitful acclimatized stocks. Again, the limbs of some plants are short, a condition likewise observed in hybrids in 1908, and do not become a factor of normal importance in the productiveness of the plant, the main axis having acquired nearly as much prominence as in the "limbless" condition referred to. Such diversities occur most frequently in newly imported stocks. In selected acclimatized stocks more uniformity of type is apparent, though diversities still exist. In general, what appears to be the most promising type of branching in Egyptian cotton is represented by plants of the Yuma stock. These plants are from 6 to 8 feet tall, with a leading axis, five or six limbs nearly as long as the main stem but loaded with fruit, and consequently spreading at an angle of from $50^{\circ}$ to $60^{\circ}$, and above them on the axis pendent fruiting branches-a plant of symmetrical, broad-spreading, inverted kite shape.

Much of the diversity in branching and in form of plant in the unacclimatized stocks of Egyptian cotton may have to be ascribed to hybridity or to reversion toward the Hindi cotton, as the indications now are that contamination exists in all Egyptian varieties, in some to a much more marked degree than in others. ${ }^{1}$

\section{EFFECTS OF PRUNING ON BRANCH DEVELOPIMENT.}

The "topping" of cotton plants has been advocated as a means of hastening the maturing of fruit, but it has never gained a place in cotton culture. It is not known that an extensive and conclusive set of tests has ever been made, though cases of whole plantings being topped have been reported. ${ }^{2}$ Its possibilities as a practical method of increasing yields have not yet been ascertained in this country,

\footnotetext{
${ }^{1}$ Cook, O. F. Hindi Cotton in Egypt. Bulletin 210, Bureau of Plant Industry, U. S. Dept. of Agricuture. 1911.

2 "It was at one time common with some growers to cut off the growing top of the cotton plant after the bolls were formed. By doing so, they maintained, the quantity of fiber was increased and its quality improved. The practice has now practically died out." See Foaden, G. P., "Cotton Culture in Egypt," Bulletin 42, Office of Experiment Stations, U. S. Dept. of Agriculture, 1897, p. 21.
} 
but it is sometimes advocated as a means of encouraging earliness and fruitfulness. The method should be tested, especially in the case of Egyptian cotton, which matures late and takes on a rank vegetative growth on fertile, well-watered soils of the lower Colorado River region in Arizona and California.

Preliminary experimentation and observation by the writer have thrown some light on the effect of topping or pruning on habits of branching, though the most conspicuous effect was to accelerate vegetable growth. When the growing tip of the axis was removed the branches at a node or two below grew more vigorously than usual and the uppermost branch, whether fruiting or vegetative, showed marked tendency to assume an upright position. When a large limb was cut back to near the point of union with the main axis the lowest bud of the severed limb or a bud at the node of the stem from which it originated grew rapidly to replace the branch removed. In the case of fruiting branches the growth was somewhat hastened, the branch became thick and rigid, and the bracts very large and coarse. Many instances of abortion of the growing tip of the main axis occur, a natural pruning, with a similar result in causing the fruiting branches to take on a resemblance to vegetative branches.

In general, it may be said that the result of pruning 40 plants at different levels of both axis and branches has been the acceleration of growth in branches just below the point of pruning. In none of these cases was it apparent that fruitfulness was increased or that the fruit already' set was matured more rapidly or opened earlier than on neighboring unpruned plants. Another effect of topping the main stem was the forcing into growth of the buds on that portion of the stem referred to as the "zone of undeveloped branches," which buds remain dormant under normal conditions.

There has been no topping of nearly mature plants to test the effect upon earliness, but it is practically demonstrated that there is no advantage in pruning young plants, as the ripening of the crop is only retarded by such a practice.

The buds at nodes of cotyledons may be forced into growth by cutting back young plants. As already recorded, buds in the axils of cotyledons normally develop in only a small proportion of plants. Series of young plants were topped below the first, second, and third true leaves. In plants pruned below the first true leaf, which left only the buds in the axils of the cotyledons, these buds developed rapidly. In plants that were topped above the third or fourth node the bud at the node next below the point of pruning usually developed most rapidly and soon took on the upright nature of the axis. Where only branches from nodes of the cotyledons were left these developed 
to form a plant in superficial appearance not unlike one of normal growth. In such instances, and in many others when rabbits pruned back the young plants below the first true leaf, the production of fruit was somewhat later than in normal plants.

\section{BRANCH DIVERSITY IN RELATION TO ENVIRONMENT.}

In several instances variations in growth and branching appeared which could be ascribed to environment. The most marked of these was the variation in length of the first internode of fruiting branches, previously referred to. In a small planting of Egyptian cotton at Los Angeles, Cal., the first internode of the fruiting branches was invariably longer than in the Egyptian cotton grown elsewhere in the Southwest, frequently attaining 11 to 13 inches. The usual length of the first internode of fruiting branches in Egyptian cotton grown at Somerton and Sacaton, Ariz., was 6 to 8 inches, an inch or two longer than the leafstalk at the same node. The leafstalks at Los Angeles were rather shorter than in Arizona, so that the first internode of the fruiting branches often was more than double the length of the petiole. The remarkable association of abbreviated leaf petioles with elongated internodes of fruiting branches was common to both imported and acclimatized stocks of Egyptian cotton at Los Angeles. Besides this these varieties, which grew to a height of 7 to 9 feet in Arizona, never exceeded $5 \frac{1}{2}$ feet in this planting and the limbs were less numerous and comparatively short, seldom reaching a length equaling two-thirds that of the main axis. The only differences in vegetative characters between the two stocks at Los Angeles were the slightly lighter green foliage of plants of the imported stock and the greater percentage in the same stock of plants bearing small bolls. This peculiar response of the plants to the Los Angeles conditions was remarkably constant.

As a rule there are from five to ten more internodes in the stem than in the largest limb. There is a tendency to a smaller development of the limbs in locations of restricted moisture than where the moisture supply is more abundant and constant. In the latter locations the largest limb may closely approximate the axis in number of the internodes.

Egyptian cotton plants growing in soil containing considerable quantities of alkali had fruiting branches postponed and regetative branches restricted. At Sacaton, Ariz., in 1910, fruiting branches appeared at the thirteenth node on the Yuma variety of plants growing on soil free from alkali. On plants growing on alkali soil fruiting branches were not put out until the sixteenth node, and five limbs developed as compared with seren on plants growing on soils without alkali. 
From observations on the plantings of Egyptian cotton at several stations in California and Arizona in 1910 it is clear that the various conditions under which the cottons were grown occasioned marked differences in the height on the stem at which fruiting branches first developed. The Yuma variety of cotton bore its first fruiting branch at node 9 (average) at Stockdale, Cal., and at node 13 at Red Bluff, Cal.; under other conditions the same variety did not fruit below node 14. The results of these observations are given in Table II.

TABLE II.-Differences in the average number of limbs and the average number of nodes below the first fruiting branch in several plantings of Egyptian cotton in the season of 1910.

\begin{tabular}{|c|c|c|c|c|}
\hline \multirow[b]{2}{*}{ Localities. } & \multicolumn{4}{|c|}{ Variety observed. } \\
\hline & $\begin{array}{c}\text { Yuma } \\
\text { (acclima- } \\
\text { tized). }\end{array}$ & $\begin{array}{l}\text { Mit Afifi } \\
\text { (unaccli- } \\
\text { matized). }\end{array}$ & $\begin{array}{l}\text { Yuma } \\
\text { (acclima- } \\
\text { tized). }\end{array}$ & $\begin{array}{l}\text { Mit Afifi } \\
\text { (unaccli- } \\
\text { matized). }\end{array}$ \\
\hline Sacaton, Ariz. (1) ................ & $\underset{6.4}{\text { Limbs. }}$ & Limbs. & $\begin{array}{l}\text { Nodes. } \\
12.6\end{array}$ & Nodes. \\
\hline Do. $(2) . \ldots \ldots$ & 4.8 & & 15 & (1) \\
\hline 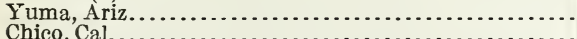 & 6.5 & 8.6 & 11 & 14.4 \\
\hline Glendale, Cal............. & 4 & $\ddot{4}$ & $\begin{array}{r}11.1 \\
8.2\end{array}$ & $\begin{array}{r}12.1 \\
9.3\end{array}$ \\
\hline Red Bluff, Cal......... & & & 11.8 & \\
\hline 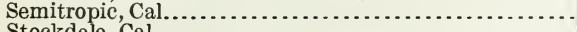 & 4.2 & 5 & 8.7 & 10.4 \\
\hline $\begin{array}{l}\text { Stockdale, Cal } \ldots \ldots \ldots \\
\text { Visalia, Cal }, \ldots \ldots\end{array}$ & & & 8 & $\begin{array}{r}9.5 \\
12.6\end{array}$ \\
\hline 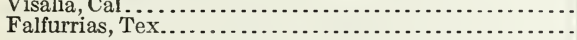 & & & $\begin{array}{l}11.4 \\
12.8\end{array}$ & \\
\hline
\end{tabular}

In the accompanying table the comparisons between Yuma (acclimatized) and Mit Afifi (unacclimatized) Egyptian cottons were made in parallel rows, except at Yuma, where the conditions of soil and culture were different for each stock. Some superiority is displayed by the Yuma cotton in producing fruiting branches at slightly lower nodes than the newly imported Mit Afifi cotton. At all stations excepting Falfurrias, Tex., irrigation was practiced. The second record of the Yuma variety at Sacaton indicates the effect of alkali soil in delaying the fruiting branches to node 16 and in restricting the limbs to five to the plant. Another condition of delayed fruiting branches caused by excessive regetative growth, exemplified in Mit Afifi grown at Yuma in 1910, is accompanied by a normally increased number of limbs. The necessity of determining the cultural requirements of low fruiting is emphasized by the occurrence of such differences within the variety. The stimulation of the plants to retain and nourish fruiting branches which are aborted or fail to develop under less favorable conditions is to be expected with confidence from improved cultural methods.

\section{EFFECTS OF LATE PLANTING ON HABITS OF BRANCHING.}

Late planting, as far as has been observed, seems to accelerate the development of limbs and to delay the growth of fruiting branches. This may be only an expression of more exuberant growth, since 
late-planted cotton in Arizona in 1909 did not suffer the retarding influence of cool nights which the early planted (Mar. 15-20) cotton experienced. The deferred appearance of fruiting branches in lateplanted cotton would not only mean a relatively later crop, but might also result in lessened fertility, as compared with early planted cotton which put out fruiting branches lower down. Late plantings of a stock of Egyptian cotton which has been grown at Sacaton, Ariz., for several years produced its first fruiting branch at node 17 (average), which was three nodes higher (later) on the plant than the first fruiting branches produced on plants alongside, grown from seed of the same stock but planted a month earlier (Mar. 22). The late plants also bore two more limbs to the plant than the earlier plants.

\section{ABNORMAL VEGETATIVE GROWTH ON PROSTRATE PLANTS.}

Plants of the most uniform acclimatized stock (Yuma) in many instances were prostrated by their own weight or blown over by storms. In such cases one of the limbs asumed an upright position and outgrew the central stalk. It was usual to find such branches with more nodes than the axis. Another effect of the prostrating of plants was the long vinelike growth of the ends of branches when their growing tips were shaded beneath dense foliage. The internodes grew to much greater length than normally, so that the end of the branch resembled a long slender whiplash. When limbs are partly broken off, secondary limbs develop at practically all of their nodes, though under normal conditions they remain dormant, especially at the lower nodes. Where several limbs are prostrate, these branches send up very numerous sprouts close together, forming veritable thickets.

\section{BRANCHING HABITS OF THE DIFFERENT EGYPTIAN VARIETIES.}

Diversity due to hybridization or reversion is so great in some of the Egyptian varieties grown in Arizona from imported seed that it is difficult to fix upon any marked constant difference between the varieties. Furthermore, the differences in soil and cultural conditions in the fields in which the several varieties were grown affected the habits of the plants to an extent which made direct comparison difficult. However, some differences appear.

Jannovitch cotton plants are more open than Mit Afifi, bearing fewer limbs, a condition which may account for the lighter yield of the Jannovitch. Both varieties grew to a height of 7 to 8 feet, but the Jannovitch took on a more spreading habit than the Mit Afifi. In the Jannovitch field the plants with their heavy, wide-spreading limbs were considerably broken down, while the Mit Afifi plants in another field remained for the most part erect. The Mit Afifi stock 
also contained many plants that showed tendencies to abort their lower fruiting branches. This semisterile condition may be an indication of hybrid contamination, although these effects might have been induced to some degree by different conditions of soil and cultivation. Nubari plants were more nearly like the best acclimatized stock in bearing fruiting branches at lower nodes on the stem than either the Jannovitch or Mit Afifi varieties as grown from imported seed, which made the Nubari comparatively more fruitful than the other imported varieties. In contrast to the erect habit of Mit Afifi and the more open habit of Jannovitch, some of the Ashmuni plants were low and bushy, producing more limbs. But this stock was so completely diverse that it was practically impossible to distinguish a typical form.

\section{CONCLUSIONS.}

The Egyptian cotton plant bears two kinds of branches, long vegetative branches on the lower part of the stem, which bear no flower buds directly, and above these, to the top of the plant, shorter fruiting branches which bear flower buds.

The differences between vegetative branches and fruiting branches are very sharp: (1) Vegetative branches usually approximate the length of the main stem, while fruiting branches are about one-third as long. (2) Vegetative branches bear no flower buds except as they produce secondary fruiting branches. Fruiting branches bear a flower bud at each node opposite the leaf. (3) The vegetative branches, like the axis, bear fruiting branches and may bear vegetative branches. The fruiting branches rarely bear fruiting branches or vegetative branches.

Vegetative branches may be either axillary or extra-axillary. Normal fruiting branches are always extra-axillary. Single bolls or short fruiting branches are sometimes developed from buds in the axillary position, at nodes bearing fruiting branches. Such branches may be regarded as secondary fruiting branches borne by the axillary vegetative branch, which is itself suppressed.

From 6 to 8 large vegetative branches are usually produced from the first 10 nodes of the axis. At the next 2 or 3 nodes the buds frequently remain dormant or are abortive, and above these a fruiting branch is produced at each node.

Under conditions of great luxuriance extra-axillary limbs occur at some of the lower nodes which would bear fruiting branches if the development of limbs was restricted.

The length and number of vegetative branches largely determine whether the plants are bushy and spreading or upright. The control of the production of vegetative branches-that is, of the stature 
of the plant-is necessary because of the desirability of small plants in cultivation and harvesting.

Egyptian cotton when planted late apparently develops more numerous regetative branches than when planted early. Early planting is therefore advisable as a means of restricting the development of regetative branches.

Abortion of early fruiting branches on both axis and large limbs is common in a greater or less degree to all stocks grown from imported seed. Even the Arizona acclimatized plants frequently abort their lowest fruiting branches.

Some of the selected acclimatized types of Egyptian cotton originated in the United States bear fruiting branches at lower nodes on the stem than the stocks of imported Egyptian cotton. Selection for low fruiting gives promise of being a practical means of increasing earliness and yield.

Of the six Egyptian varieties grown in Arizona in 1909 from imported seed, Nubari most nearly resembled the acclimatized stocks in putting out fruiting branches at comparatively low nodes of the stem.

A method of recording branching habits of cotton by means of diagrams has been devised. The diagrams show the location of branches, the development of fruiting branches, and the stature of plants. Such diagrams promise to be of value as records in the cultural and breeding study of cotton. (See pp. 16-17.)

Preliminary experiments in "topping" young plants have resulted in stimulating the growth of buds in the axils of cotyledons. Branches just below the point where the plant is topped make an excessive vegetative growth and tend to assume an upright position in place of the severed axis. The topping of nearly mature plants to hasten the ripening of fruit has not yet been adequately tested.

Egyptian cotton plants grown on soil containing considerable alkali restrict the development of limbs and reject their early fruiting branches.

Differences in the branching habits of the different Egyptian varieties grown from imported seed are not sharply defined because of the diversity within each variety and hence can not at present be used to distinguish one variety from another. 

